University of Nebraska - Lincoln

DigitalCommons@University of Nebraska - Lincoln

US Army Research

U.S. Department of Defense

2012

\title{
Epidemiology of cervical spine fractures in the US military
}

Andrew J. Schoenfeld

Texas Tech University Health Sciences Center, ajschoen@neoucom.edu

Bernadette Sielski

Texas Tech University Health Sciences Center

Kenneth P. Rivera

Texas Tech University Health Sciences Center

Julia O. Bader

University of Texas at El Paso

Mitchel B. Harris

Harvard Medical School

Follow this and additional works at: https://digitalcommons.unl.edu/usarmyresearch

Schoenfeld, Andrew J.; Sielski, Bernadette; Rivera, Kenneth P.; Bader, Julia O.; and Harris, Mitchel B., "Epidemiology of cervical spine fractures in the US military" (2012). US Army Research. 222.

https://digitalcommons.unl.edu/usarmyresearch/222

This Article is brought to you for free and open access by the U.S. Department of Defense at DigitalCommons@University of Nebraska - Lincoln. It has been accepted for inclusion in US Army Research by an authorized administrator of DigitalCommons@University of Nebraska - Lincoln. 


\title{
Epidemiology of cervical spine fractures in the US military
}

\author{
Andrew J. Schoenfeld, MD ${ }^{\mathrm{a}, *}$, Bernadette Sielski, DO ${ }^{\mathrm{a}}$, Kenneth P. Rivera, MS, PA-C ${ }^{\mathrm{a}, \mathrm{b}}$, \\ Julia O. Bader, $\mathrm{PhD}^{\mathrm{c}}$, Mitchel B. Harris, MD, FACS ${ }^{\mathrm{d}}$ \\ ${ }^{a}$ Department of Orthopaedic Surgery, William Beaumont Army Medical Center, Texas Tech University Health Sciences Center, \\ 5005 N. Piedras St, El Paso, TX 79920, USA \\ ${ }^{\mathrm{b}}$ Department of Graduate Biomedical Sciences, Baylor University, El Paso 79920, TX, USA \\ ${ }^{\mathrm{c}}$ Department of Mathematical Sciences, University of Texas at El Paso, El Paso 79902, TX, USA \\ ${ }^{\mathrm{d}}$ Department of Orthopaedic Surgery, Brigham and Women's Hospital, Harvard Medical School, Boston, MA 02115, USA \\ Received 8 October 2010; revised 21 December 2010; accepted 26 January 2011
}

Abstract

BACKGROUND CONTEXT: The epidemiology of cervical spine fractures and associated spinal cord injury (SCI) has not previously been estimated within the American population.

PURPOSE: To determine the incidence of cervical spine fractures and associated SCI and identify potential risk factors for these injuries in a large multicultural military population.

STUDY DESIGN: Query of a prospectively collected military database.

PATIENT SAMPLE: The 13,813,333 military servicemembers serving in the US Armed Forces between 2000 and 2009.

OUTCOME MEASURES: The Defense Medical Epidemiology Database (DMED) was queried to identify all servicemembers diagnosed with cervical spine fractures with and without SCI during the time period under investigation. Data were used to determine the incidence of cervical spine fractures and SCI as well as identify risk factors for their development.

METHODS: The DMED was queried for the years 2000 to 2009 using the International Classification of Diseases, Ninth Revision, Clinical Modification code for cervical spine fractures with and without SCI (805.0, 805.1, 806.0, and 806.1). The database was also used to determine the total number of servicemembers within the military during the same period. The incidence of cervical spine fractures and fractures associated with SCI was determined, and unadjusted incidence rates were calculated for the demographic characteristics of sex, race, military rank, branch of service, and age. Adjusted incidence rate ratios were then determined using multivariate Poisson regression analysis to control for other factors in the model and identify significant risk factors for cervical spine fractures and cervical injuries associated with SCI.

RESULTS: From 2000 to 2009, there were 4,048 cervical spine fractures in a population at risk of $13,813,333$ servicemembers. The overall incidence of cervical spine fractures was 0.29 per 1,000 person-years, and the incidence of fracture associated SCI was 70 per 1,000,000. The cohorts at highest risk of cervical spine fracture were males, whites, Enlisted personnel, those serving in the Army, Navy, or Marine Corps, and servicemembers aged 20 to 29. Risk of fractureassociated SCI was significantly increased in males, Enlisted personnel, servicemembers in the Army, Navy, or Marines, and those aged 20 to 29.

CONCLUSIONS: This study is the largest population-based investigation to be conducted within the United States regarding the incidence of SCI and the only study addressing incidence and risk factors for cervical spine fractures. Male sex, white race, Enlisted military rank, service in the

FDA device/drug status: Not applicable.

AJS: Nothing to disclose. BS: Nothing to disclose. KPR: Nothing to disclose. JOB: Nothing to disclose. $\boldsymbol{M B H}$ : Speaking/teaching Arrangements: AO Spine (None); Research Support (staff/materials): Synthes Spine (E); Fellowship Support: Synthes Spine (Disclosed in Research Support).

Some of the authors of this manuscript are members of the US military and employees of the US Government. The opinions or assertions contained herein are the private views of the authors and are not to be construed as official or reflecting the views of the Department of Defense, the US Government, or William Beaumont Army Medical Center.

* Corresponding author. Department of Orthopaedic Surgery, William Beaumont Army Medical Center, Texas Tech University Health Sciences Center, 5005 N. Piedras St, El Paso, TX 79920, USA. Tel.: (915) 569-1830.

E-mail address: ajschoen@neoucom.edu (A.J. Schoenfeld) 
Army, Navy, or Marine Corps, and ages 20 to 29 were found to significantly increase the risk for cervical fractures and/or fracture associated SCI. Our findings support previously published data but also represent best available evidence based on the size and diversity of the population under study. LEVEL OF EVIDENCE: Prognostic; Level II. Published by Elsevier Inc.

Keywords: $\quad$ Cervical; Fracture; Spinal cord injury; Incidence; Epidemiology

\section{Introduction}

Cervical spine fractures are frequently seen in association with trauma, particularly among younger individuals [1-3]. These injuries, which exist on a spectrum from minor avulsion fractures to significant fractures in association with spinal instability and spinal cord injury (SCI), can exert an enormous direct financial toll on the health care system. The even greater significance of these injuries is because of the indirect losses including time off work and lost productivity, especially in young patients who sustain complete SCIs $[4,5]$. In the last two decades, advances have occurred in regard to both the surgical and medical management of patients with cervical fractures, as well as SCIs. However, the epidemiology of spinal injuries and cervical spine fractures, in particular, remain incompletely explored. A recent search of the medical literature reveals that no prior investigation has attempted to quantify the incidence of cervical spine fractures or characterize risk factors for these injuries, among a large and diverse population base.

Although some studies have attempted to address other subsets of spinal trauma [1-3,6-13], or spinal injuries as a whole [14], most of these investigations are limited in scope and frequently rely on populations already exposed to trauma. Based on the results of these prior investigations, male sex $[6,7,10,11,15]$, white race $[10,11]$, lower socioeconomic or educational status [14], high-risk behaviors $[4,14,15]$, and age 15 to 30 years $[3,7,10]$ have all been postulated as potential risk factors for spinal fracture and/or SCI.

Determinations of the incidence of SCI or spinal fractures made using trauma-based populations, or those presenting to a single practice or center, likely result in overestimations [16]. Furthermore, available data regarding the epidemiology of spinal fractures or SCI are not necessarily translatable to the cervical spine, and calculations for select populations in trauma centers or regional locations should not be assumed to apply to the population as a whole.

The major difficulty in epidemiologic investigations regarding spinal injury consists of the inability to define the entire population at risk. In several studies, conducted outside the United States, complete populations at risk have been determined using nationalized health insurance databases or government registries $[7,14]$. Within the US health care system, such determinations are not possible and studies have been limited to using smaller population-based assessments from states or counties $[8,13,15]$. However, the Defense Medical Epidemiology Database (DMED), maintained by the Department of Defense, represents a closed health care data set for an American population similar to those used in countries with nationalized health delivery systems and registries [17]. The DMED is linked to the Department of Defense Ambulatory Data System, and the military's Composite Health Care System, which enables the successful documentation of all medical and demographic data for every servicemember in the US Armed Forces, even those who receive their medical treatment at nonmilitary facilities [17].

The DMED can be queried by approved personnel to provide accurate reports regarding the total number of servicemembers within the US Armed Forces at any given time and demographic data regarding servicemembers' age, sex, race, military rank, and branch of service. Most importantly, the DMED can be used to determine the total number of servicemembers diagnosed with any medical condition as classified by International Classification of Diseases, Ninth Revision, Clinical Modification code. The DMED has been successfully used in the past to estimate the epidemiology of traumatic [18], degenerative [19,20], and spinal conditions [21] within the population of the US military.

Based on the demographic composition and occupational demands of the US Armed Forces, data from prior reports on spinal fractures and SCI indicate that military servicemembers would be at high risk for such injuries. The goal of this investigation was to quantify the incidence and determine risk factors for cervical fractures, with and without SCI, among servicemembers serving in the US military from 2000 to 2009. To the best of our knowledge, this study is the first to estimate the incidence of SCI among an American population not limited to one geographic location. Additionally, it is the only report to specifically document the incidence and risk factors for cervical fractures.

\section{Materials and methods}

This study was conducted after approval from our institutional investigational review board. The database containing the DMED was queried to capture all military servicemembers who sustained cervical fractures in the 10-year period from 2000 to 2009. The International Classification of Diseases, Ninth Revision, Clinical Modification 
codes for open and closed cervical spine fractures, as well as those with and without SCI were used in the query $(805.0,805.1,806.0$, and 806.1). To prevent the possibility of overestimation, related codes specific to the site of cervical injury were not used. Additionally, those individuals with SCI but no evidence of cervical spine fracture by International Classification of Diseases, Ninth Revision, Clinical Modification code were not included. Last, the search was limited to first time diagnoses only so that subsequent diagnoses, made in the outpatient setting as servicemembers received further care for their injuries, were not counted as separate incidents.

All servicemembers identified in the DMED as having sustained a cervical spine fracture were entered into our data set, along with their sex, age, race, military rank, and branch of service within the Department of Defense. The DMED classifies race as white, black, or other where other may denote Hispanic, Native American, Alaskan Native, Pacific Islander, Asian, mixed race, or no race reported by the servicemember. All racial statistics contained within the DMED are determined by servicemember self-report. Similarly, age within the database is categorized within six age groups; $<20$ years, 20 to 24 years, 25 to 29 years, 30 to 34 years, 35 to 39 years, and 40 years and older.

Branch of service in the DMED is limited to Army, Navy, Air Force, or Marine Corps, and specific military occupational specialty (ie, infantryman, cavalry scout, surgeon, cook, and so on) is not accessible. Rank is classified as Junior Enlisted (private to specialist/corporal), Senior Enlisted (Sergeant to Sergeant Major), Junior Officers (Second Lieutenant to Captain, and Warrant Officers), and Senior Officers (Major to Lieutenant General). Prior studies using the DMED have used rank and branch of service as proxies for activity level, with combat arms branches such as the Army and Marine Corps assumed to have higher occupational demands on average [19-21]. Similarly, Enlisted servicemembers are also assumed, on average, to engage in more physical occupational demands on a daily basis than are officers [21]. Military rank can also be used as a proxy for socioeconomic status both within the military and before enlistment [22-24]. Enlisted servicemembers, and especially the Junior Enlisted, make less money than officers [25], are less likely to have a college degree, and often times derive from lower socioeconomic strata within the general population [22-24].

The DMED was also queried for data pertaining to the entire Armed Forces population categorized by sex, race, age, rank, and branch of service for the period under study. For the purposes of this investigation, the entire military population from 2000 to 2009 was considered the population at risk. All data were contained in a Microsoft Excel spreadsheet in a password-protected personal computer, and statistical analyses were performed using Statistical Analysis Software (SAS 9.2; Cary, NC, USA).

The incidence of cervical spine fractures as a whole, as well as the incidence of cervical fractures associated with

\section{EVIDENCE $\bigcirc$ METHODS}

\section{Context}

There is a paucity of epidemiological information regarding cervical spine fractures in the U.S. military and the U.S. population generally. This study aims to begin filling this void.

\section{Contribution}

Using a large military database containing nearly 14 million study subjects, the incidence of cervical spine fracture was 0.29 per 1,000 person-years, and the incidence of fractures with associated spinal cord injury was 70 per 1 million. Age and sex (young and men) predicted more injuries, as did branch of service (Army and Marine Corps), suggesting different social or physical exposure patterns.

\section{Implication}

This study is the largest population-based investigation into the incidence of cervical fractures and spinal cord injuries reported in the United States. The limitations inherent in all large database assessments hold, such as minimally detailed dataset, specific population, and various other factors.

- The Editors

SCI, was calculated by comparing the number of servicemembers diagnosed with these injuries to the entire population at risk. The incidence is expressed as the rate per 1,000 person-years, where one person-year represents a single calendar year of exposure to military service. Unadjusted incidence rates (IRs) were calculated for all risk factors of interest (sex, race, military rank, branch of service, and age) for all cervical spine fractures and cervical fractures associated with SCI.

Adjusted incidence rate ratios (IRRs) and 95\% confidence intervals were then determined using multivariate Poisson regression analysis that controlled for the other factors in the model. Adjusted IRRs were determined for all potential risk factors using a single group within the category of interest as a referent. For sex, rank, branch of service, and age, the referent was always established as the group within the risk factor category with the lowest unadjusted IR. In the case of race, only black or white were considered viable choices for the referent because of the fact that the category of other encompassed many disparate racial and ethnic groups.

\section{Results}

In the time period under study, there were 4,048 cervical spine fractures documented and treated within the military 
Table 1

Unadjusted IR and adjusted IRRs of cervical fractures among US military servicemembers, 2000-2009

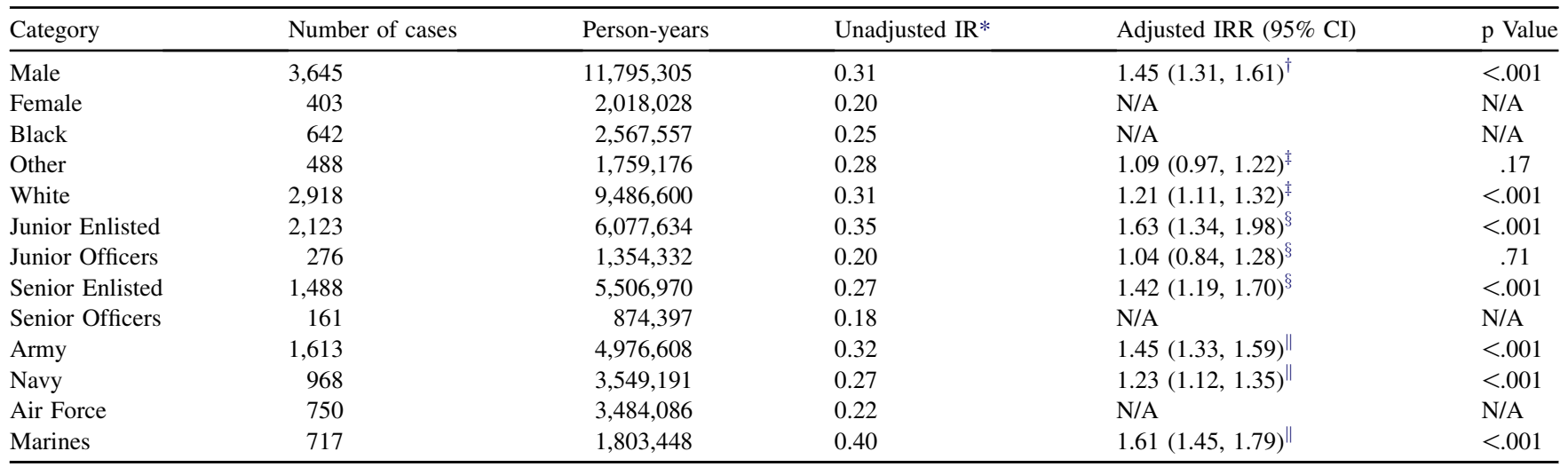

IRR, incidence rate ratio; IR, incidence rate; CI, confidence interval; N/A, not applicable because this category was used as the referent category for calculations.

* Incidence rate is per 1,000 person-years.

$\dagger$ Adjusted for age, race, rank group, and service. Female was the referent category.

$¥$ Adjusted for age, sex, rank group, and service. Black was the referent category.

$\S$ Adjusted for age, sex, race, and service. Senior Officers were the referent category.

" Adjusted for age, sex, race, and rank group. Air Force was the referent category.

population of 13,813,333 servicemembers. Cervical fractures without SCI occurred in 3,106 individuals, whereas 942 sustained SCIs in association with their fractures. The incidence of cervical spine fractures in this population was 0.29 per 1,000 person-years, and the incidence of fractureassociated SCI was 0.07 per 1,000 person-years or 70 per $1,000,000$ person-years. Unadjusted IRs indicated that males, white servicemembers, Junior Enlisted personnel, Marines, and those aged 20 to 24 years were at greatest risk of cervical spine fracture (Tables 1 and 2). Unadjusted IRs for fractures associated with SCI revealed similar results (Tables 3 and 4). The highest unadjusted IR for cervical fracture, as well as fracture-associated SCI, was encountered among members of the Marine Corps, at 0.40 and 0.10 per 1,000 person-years, respectively.

Most of the risk factors identified in the unadjusted analyses were confirmed as having a significant association with

Table 2

Incidence rate ratio of cervical fractures among servicemembers in the US military, 2000-2009, by age group

\begin{tabular}{lrllll}
\hline Age group & $\begin{array}{l}\text { No. of } \\
\text { cases }\end{array}$ & Person-years & IR* $^{*}$ & Adjusted IRR $(\mathrm{CI})^{\dagger}$ & $\begin{array}{l}\mathrm{p} \\
\text { Value }\end{array}$ \\
\hline$<20$ & 341 & $1,084,882$ & 0.31 & $1.06(0.89,1.25)$ & .53 \\
$20-24$ & 1,631 & $4,613,200$ & 0.35 & $1.25(1.09,1.43)$ & .001 \\
$25-29$ & 855 & $2,919,000$ & 0.29 & $1.18(1.04,1.33)$ & .01 \\
$30-34$ & 495 & $1,996,712$ & 0.25 & $1.06(0.93,1.21)$ & .39 \\
$35-39$ & 402 & $1,773,252$ & 0.23 & N/A & N/A \\
$40+$ & 324 & $1,426,287$ & 0.23 & $1.07(0.92,1.25)$ & .35 \\
\hline
\end{tabular}

IRR, incidence rate ratio; IR, incidence rate; CI, confidence interval; N/A, not applicable because this category was used as the referent.

* Incidence rate is per 1,000 person-years.

$\dagger$ Adjusted for sex, service, rank group and race. The 35- to 39-yearold group was used as the referent category. the incidence of cervical fractures, and fractures associated with SCI, after multivariate Poisson regression analysis. Male sex significantly increased the risk of cervical fracture when compared with females (Table 1). White race, Enlisted rank, and service in the Army, Navy, and Marines were also found to significantly increase cervical fracture risk relative to black servicemembers, Senior Officers, and members of the Air Force (Table 1). Servicemembers aged 20 to 29 years were at significantly increased risk of fractures compared with those aged 35 to 39 years (Table 2). The highest adjusted IRR for cervical fractures was found among those serving in the Marine Corps (adjusted IRR 1.61 [95\% confidence interval, 1.45-1.79]).

Multivariate Poisson regression analysis maintained male sex, Enlisted rank, and Army, Navy, or Marine service as significant risk factors for cervical fractures with SCI (Table 3). Once again, those aged 20 to 29 years were identified as being at significant risk for these injuries compared with those aged 35 to 39 years, although there was only borderline significance for individuals aged 25 to 29 years $(\mathrm{p}=.046$, Table 4). White servicemembers did not have a significantly increased risk of cervical fracture with SCI when compared with those who were black. Similar to findings for cervical fractures as a whole, service in the Marine Corps exhibited the highest adjusted IRR for cervical fractures with SCI (adjusted IRR 2.04 [95\% confidence interval, 1.64-2.53]).

\section{Discussion}

Cervical spine fractures and associated SCIs are most frequently encountered among young individuals and often 
Table 3

Unadjusted IRs and adjusted IRRs of cervical fractures associated with SCI among US military servicemembers, 2000-2009

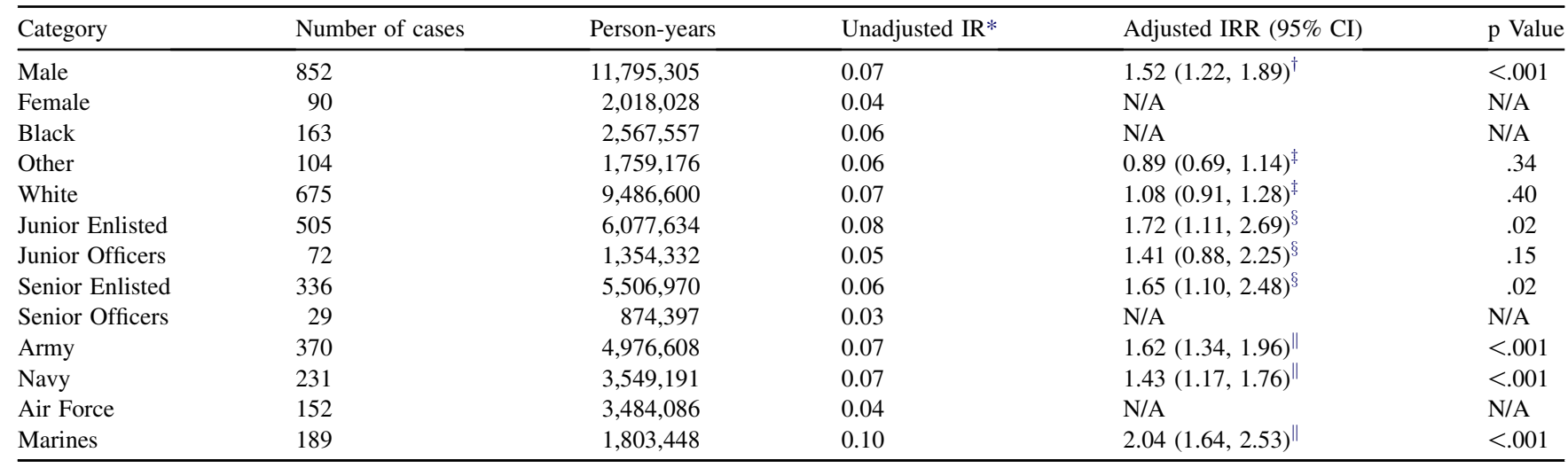

IRR, incidence rate ratio; IR, incidence rate; CI, confidence interval; N/A, not applicable because this category was used as the referent category for calculations.

* Incidence rate is per 1,000 person-years.

$\dagger$ Adjusted for age, race, rank group, and service. Female was the referent category.

₹ Adjusted for age, sex, rank group, and service. Black was the referent category.

$\S$ Adjusted for age, sex, race, and service. Senior Officers were the referent category.

$\|$ Adjusted for age, sex, race, and rank group. Air Force was the referent category.

occur as a result of trauma $[4,9,14,15]$. These injuries present a substantial public health problem, as they not only lead to long-term lost productivity but also incur significant medical costs $[4,5]$. In most instances, the quality of life for an individual is permanently altered in the face of SCI, and risks of subsequent morbidity and mortality are increased [4].

The annual incidence of SCI among the US population has been estimated at 40 per $1,000,000[12,13,15]$, with 11,000 new cases occurring per year [12,15]. Although a great deal of research has appropriately been devoted to surgical and medical endeavors capable of halting the SCI process, as well as treating those with cervical spine fractures, the epidemiology of these injuries is incompletely understood, especially in the American population.

No previous research has attempted to estimate the incidence of cervical spine fractures or establish risk factors for

Table 4

Incidence rate ratio of cervical fractures associated with SCI among servicemembers in the US military, 2000-2009, by age group

\begin{tabular}{lcllll}
\hline Age group & $\begin{array}{l}\text { No. of } \\
\text { cases }\end{array}$ & Person-years & IR* $^{*}$ & Adjusted IRR $(\mathrm{CI})^{\dagger}$ & $\begin{array}{l}\mathrm{p} \\
\text { Value }\end{array}$ \\
\hline$<20$ & 88 & $1,084,882$ & 0.08 & $1.32(0.93,1.87)$ & .12 \\
$20-24$ & 398 & $4,613,200$ & 0.09 & $1.47(1.11,1.94)$ & .007 \\
$25-29$ & 206 & $2,919,000$ & 0.07 & $1.30(1.01,1.69)$ & .046 \\
$30-34$ & 96 & $1,996,712$ & 0.05 & $0.92(0.69,1.24)$ & .60 \\
$35-39$ & 88 & $1,773,252$ & 0.05 & N/A & N/A \\
$40+$ & 66 & $1,426,287$ & 0.05 & $1.04(0.75,1.44)$ & .82 \\
\hline
\end{tabular}

IRR, incidence rate ratio; IR, incidence rate; N/A, not applicable because this category was used as the referent.

* Incidence rate is per 1,000 person-years.

$\dagger$ Adjusted for sex, service, rank group, and race. The 35- to 39-yearold group was used as the referent category. their occurrence. The investigations that have been conducted in regard to spinal injuries as a whole, or SCI, are limited in most cases by select populations $[1,15]$, inclusion of patients who have already sustained trauma [6,9-11], and localization in one trauma center or region $[2,3,8,13]$. Only two prior investigations have attempted to quantify incidence and risk factors for spinal fractures and/or SCI among large well-defined populations at risk, and both these studies were performed in Canada [7,14]. Hu et al. [14] reported that the incidence of spinal fractures as a whole in Manitoba was 0.64 per 1,000 person-years, whereas the incidence of SCI was 40 per $1,000,000$. In Alberta, Dryden et al. [7] found the incidence of SCI to be 52.5 per 1,000,000. Within the United States, largescale epidemiologic studies have focused only on states or counties and address only SCI $[8,13,15]$. The incidence of traumatic SCI in Olmstead County, Minnesota was reported to be 54.8 per $1,000,000$ from 1935 to 1981 [8]. In New York State from 1982 to 1988, the incidence was 43 per $1,000,000$ [15], whereas it was 40 per $1,000,000$ from 1988 to 1990 in Oklahoma [13].

Studies specific to cervical spine injuries are even more limited, as they tend to rely on data from single centers or trauma-specific populations. For example, Lowery et al. [11] reported a $2.4 \%$ incidence of cervical spine injury that was derived from patients enrolled in the National Emergency X-Radiography Utilization Study. Similarly, the calculation of $4.3 \%$ by Grossman et al. [9] was obtained from surveys of US trauma centers and contrasts with the $1.7 \%$ incidence encountered by retrospective review of trauma admissions by Demetriades et al. [2] at Los Angeles County and University of Southern California Medical Center from 1993 to 1997. 
This investigation sought to quantify the incidence of cervical spine fractures and fracture-associated SCI among the US military population during the years 2000 to 2009. The study also attempted to identify potential demographic risk factors for cervical fractures and SCI in this large and diverse population. Results presented here establish the incidence of cervical spine fractures within this military population as 0.29 per 1,000 person-years, whereas the incidence of fracture-associated SCI was found to be 70 per 1,000,000. Male sex, white race, ages 20 to 29 years, Enlisted military rank, and service in the Army, Navy, or Marine Corps were found to be significant risk factors for cervical spine fracture and/or SCI.

The raw incidence for cervical fractures presented here fits with the only other population-based estimate for spinal fractures [14]. In their study on the incidence of spinal fractures as a whole, $\mathrm{Hu}$ et al. [14] reported a 0.64 per 1,000 person-year incidence but did not differentiate between spinal regions. The incidence of SCI in this population is somewhat higher than that encountered in previous studies, including those conducted within the United States $[1,13,15]$. Dryden et al. [7] reported the incidence of SCI in Alberta, Canada, to be 52.5 per 1,000,000. These discrepancies may be attributable to the fact that because of the size of our population at risk, the estimations in the present study are more accurate than prior reports. However, we cannot rule out the fact that military personnel may inherently be at greater risk of cervical spine fracture and/or SCI than the general population because of occupational demands and engagement in military conflicts overseas [26].

The risk factors identified in this study are similar to those previously reported for spinal fracture and SCI in other studies in the literature $[1,2,6,7,10,11,14,15] . \mathrm{Hu}$ et al. [14] maintained that male sex, lower socioeconomic status, and age less than 30 years increased the risk of spinal fracture. Dryden et al. [7] reported male sex and ages 15 to 29 years as significant risk factors for SCI. Lowery et al. [11] found male sex, white race, and ages 15-45 years associated with an increased risk of cervical spine injury. Males, white servicemembers, and those aged 20 to 29 years were found to be at significantly increased risk of cervical fracture and/or SCI in this study. We also identified Enlisted military rank as a predictor of the risk for these injuries. This may represent the influence of socioeconomic status on the risk of cervical spine injuries; however, we cannot eliminate the potential for confounding in this area because of the fact that Enlisted individuals are more likely to be injured in military conflicts [26]. This fact can be further appreciated when one considers that the combat arms branches of the military (Army and Marines) carried a significantly increased risk of cervical fracture and SCI when compared with the Air Force.

We recognize that there are limitations to the present investigation. Foremost, this was a database study, derived from an electronic system maintained by the Department of Defense, and information used in this investigation is limited to that available in the data set. For example, it may have been useful to describe the precise level of cervical injury, understand the military occupation of those who incurred cervical fractures, and capture other demographic characteristics such as level of education, smoking status, and alcohol or drug use that have been shown to increase the risk of spinal injuries in other studies [4,14,15]. Unfortunately, as this information is not contained within the DMED, such potential confounders cannot be described.

Additionally, we were unable to determine the mechanism through which cervical spine fractures occurred. There is a possibility that the incidences reported here are overestimations when compared with the general incidence for the American population, as combat service undoubtedly increases the risk of cervical spine fractures and SCI [26]. However, the DMED's link with the military's Ambulatory Data and Composite Health Care Systems represents the fact that this data set was never intended to focus on wartime injuries. Prior military studies have estimated that only a small proportion of combat-related injuries are actually captured within the DMED [27]. Therefore, it is entirely possible that most injuries encountered in this database occurred in civilian situations and not in combat-related events.

Last, although this is a large American population study, that encompasses a diverse population on racial, socioeconomic, and gender-based grounds, the US military is not necessarily representative of the population as a whole. Specifically, according to census data, individuals serving in the military would only be representative of approximately $58 \%$ of the American population based on age [28]. Additionally, while the proportion of black servicemembers in the military approximates that of the US population as a whole, men are disproportionately represented in the armed forces when compared with women. These factors, however, should not be seen as influencing our analyses, in that multivariate testing was performed that controlled for factors such as age, and gender, within the model. As recognized above, we also cannot exclude the fact that service in the armed forces may put individuals at greater risk of spinal trauma through exposure to combat training, as well as combat environments [26,27].

Although recognizing these limitations, it is important to note that this study is the largest population-based investigation to be conducted within the US focusing on the incidence of SCI and the only study to address the incidence, epidemiology, and associated risk factors for cervical spine fractures. Findings presented in this report support prior studies and may represent the best available evidence because of the size and diversity of the population under study. Undoubtedly, further research must be performed across large cross-sections of the American population before true determinations can be made regarding the incidence of these injuries and risk factors for their development. 


\section{References}

[1] Bohlman HH. Acute fractures and dislocations of the cervical spine. J Bone Joint Surg Am 1979;61:1119-42.

[2] Demetriades D, Charalambides K, Chahwan S, et al. Nonskeletal cervical spine injuries: epidemiology and diagnostic pitfalls. J Trauma 2000;48:724-7.

[3] Ryan MD, Henderson JJ. The epidemiology of fractures and fracturedislocations of the cervical spine. Injury 1992;23:38-40.

[4] Qureshi S, Hecht AC. Epidemiology of spinal cord injury. In: Kim DH, Ludwig SC, Vaccaro AR, Change JC, editors. Atlas of spine trauma: adult and pediatric. Philadelphia, PA: Saunders, 2008:1-10.

[5] Tator CH, Duncan EG, Edmonds VE, et al. Complications and costs of management of acute spinal cord injury. Paraplegia 1993;31: 700-14.

[6] Burney RE, Maio RF, Maynard F, Karunas R. Incidence, characteristics, and outcome of spinal cord injury at trauma centers in North America. Arch Surg 1993;128:596-9.

[7] Dryden DM, Saunders LD, Rowe BH, et al. The epidemiology of traumatic spinal cord injury in Alberta, Canada. Can J Neurol Sci 2003;30:113-21.

[8] Griffin MR, Opitz JL, Kurland LT, et al. Traumatic spinal cord injury in Olmstead County, Minnesota, 1935-1981. Am J Epidemiol 1985;121:884-95.

[9] Grossman MD, Reilly PM, Gillett T, Gillett D. National survey of the incidence of cervical spine injury and approach to cervical spine clearance in US trauma centers. J Trauma 1999;47:684-90.

[10] Jackson AB, Dijkers M, Devivo M, Poczatek RB. A demographic profile of new traumatic spinal cord injuries: change and stability over 30 years. Arch Phys Med Rehabil 2004;85:1740-8.

[11] Lowery DW, Wald MM, Browne BJ, et al, NEXUS Group. Epidemiology of cervical spine injury victims. Ann Emerg Med 2001;38:12-6.

[12] McKinley W, Santos K, Meade M, Brooke K. Incidence and outcomes of spinal cord injury: clinical syndromes. J Spinal Cord Med 2007;30:215-24.

[13] Price C, Makintubee S, hernodon W, Istre GR. Epidemiology of traumatic spinal cord injury and acute hospitalization and rehabilitation charges for spinal cord injuries in Oklahoma, 1988-1990. Am J Epidemiol 1994;139:37-47.

[14] Hu R, Mustard CA, Burns C. Epidemiology of incident spinal fracture in a complete population. Spine 1996;21:492-9.
[15] Sekhon LHS, Fehlings MG. Epidemiology, demographics, and pathophysiology of acute spinal cord injury. Spine 2001;26:S2-12.

[16] Payne SR, Waller JA. Trauma registry and trauma center biases in injury research. J Trauma 1989;29:424-9.

[17] Army Medical Surveillance Activity. Defense Medical Epidemiological Database (DMED) Users Guide. Version 3.6.4. March 2004. Available at: http://www.afhsc.mil/viewDocument?file=DMED_User guide/DMEDUsersGuide364.pdf. Accessed March 7, 2010.

[18] Owens BD, Dawson L, Burks R, Cameron KL. Incidence of shoulder dislocation in the United States military: demographic considerations from a high-risk population. J Bone Joint Surg Am 2009;91:791-6.

[19] Scher DL, Belmont PJ Jr, Bear R, et al. The incidence of plantar fasciitis in the United States military. J Bone Joint Surg Am 2009;91: 2867-72.

[20] Scher DL, Belmont PJ Jr, Mountcastle SB, Owens BD. The incidence of primary hip osteoarthritis in active duty US military servicemembers. Arthritis Rheum 2009;61:468-75.

[21] Knox J, Orchowski J, Belmont PJ Jr, et al. Incidence and risk factors for low back pain in active duty military over a 10 year period. Spine J 2009;9(10S):118S-9S.

[22] Clark JB, Holt VL, Miser F. Unintended pregnancy among female soldiers presenting for prenatal care at Madigan Army Medical Center. Mil Med 1998;163:444-8.

[23] Clark JY, Thompson IM. Military rank as a measure of socioeconomic status and survival from prostate cancer. South Med J 1994;87:1141-4.

[24] Tarman GJ, Kane CJ, Moul JW, et al. Impact of socioeconomic status and race on clinical parameters of patients undergoing radical prostatectomy in an equal access health care system. Urology 2000;56:1016-20.

[25] Dalessandro RJ. Army officer's guide. 51st ed. Mechanicsburg, PA: Stackpole Books, 2009.

[26] Belmont PJ, Schoenfeld AJ, Goodman G. Epidemiology of combat wounds in Operation Iraqi Freedom and Operation Enduring Freedom: orthopaedic burden of disease. J Surg Orthop Adv 2010;19:2-7.

[27] Owens BD, Kragh JF Jr, Macaitis J, et al. Characterization of extremity wounds in Operation Iraqi Freedom and Operation Enduring Freedom. J Orthop Trauma 2007;21:254-7.

[28] United States Census Bureau. Population and household economic topics. Available at: http://www.census.gov/population/www/. Accessed September 7, 2010. 